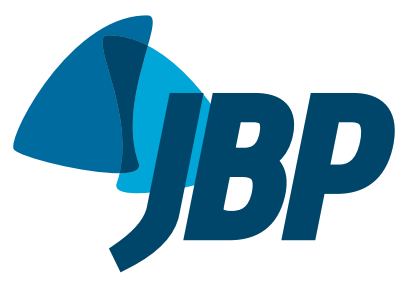

\title{
Evaluation of quality of life according to asthma control and asthma severity in children and adolescents
}

\author{
Natasha Yumi Matsunaga', Maria Angela Gonçalves de Oliveira Ribeiro², \\ Ivete Alonso Bredda Saad ${ }^{3}$, André Moreno Morcillo ${ }^{4}$, José Dirceu Ribeiro ${ }^{2,5}$ \\ Adyléia Aparecida Dalbo Contrera Toro ${ }^{2,5}$
}

1. Programa de Pós-Graduação em Saúde da Criança e do Adolescente, Faculdade de Ciências Médicas, Universidade Estadual de Campinas - Unicamp Campinas (SP) Brasil.

2. Laboratório de Fisiologia Pulmonar, Centro de Investigação em Pediatria, Faculdade de Ciências Médicas, Universidade Estadual de Campinas Unicamp - Campinas (SP) Brasil.

3. Curso de Fisioterapia nas Disfunções Cardiorrespiratórias, Faculdade de Ciências Médicas, Universidade Estadual de Campinas - Unicamp Campinas (SP) Brasil.

4. Departamento de Pediatria, Faculdade de Ciências Médicas, Universidade Estadual de Campinas - Unicamp Campinas (SP) Brasil.

5. Setor de Pneumologia Pediátrica, Departamento de Pediatria, Faculdade de Ciências Médicas, Universidade Estadual de Campinas - Unicamp Campinas (SP) Brasil.

Submitted: 29 July 2015

Accepted: 3 November 2015

\begin{abstract}
Objective: To evaluate quality of life according to the level of asthma control and degree of asthma severity in children and adolescents. Methods: We selected children and adolescents with asthma (7-17 years of age) from the Pediatric Pulmonology Outpatient Clinic of the State University of Campinas Hospital de Clínicas, located in the city of Campinas, Brazil. Asthma control and asthma severity were assessed by the Asthma Control Test and by the questionnaire based on the Global Initiative for Asthma, respectively. The patients also completed the Paediatric Asthma Quality of Life Questionnaire (PAQLQ), validated for use in Brazil, in order to evaluate their quality of life. Results: The mean age of the patients was $11.22 \pm 2.91$ years, with a median of 11.20 (7.00-17.60) years. We selected 100 patients, of whom 27, 33, and 40 were classified as having controlled asthma (CA), partially controlled asthma (PCA), and uncontrolled asthma (UA), respectively. As for asthma severity, 34, 19, and 47 were classified as having mild asthma (MiA), moderate asthma (MoA), and severe asthma (SA), respectively. The CA and the PCA groups, when compared with the NCA group, showed higher values for the overall PAQLQ score and all PAQLQ domains (activity limitation, symptoms, and emotional function; $p<0.001$ for all). The MiA group showed higher scores for all of the PAQLQ components than did the MoA and SA groups. Conclusions: Quality of life appears to be directly related to asthma control and asthma severity in children and adolescents, being better when asthma is well controlled and asthma severity is lower.

Keywords: Asthma; Quality of life; Child; Adolescent.
\end{abstract}

Study carried out at the Laboratório de

Fisiologia Pulmonar, Centro de Investigação

em Pediatria, Faculdade de Ciências

Médicas, Universidade Estadual de

Campinas - Unicamp - Campinas (SP) Brasil.

\section{INTRODUCTION}

Asthma is a heterogeneous chronic inflammatory disease, characterized by recurrent episodes of wheezing, dyspnea, chest tightness, and cough, that is very common in children and adolescents. ${ }^{(1,2)}$ Asthma is considered a global health problem and affects approximately 300 million people worldwide; in Brazil, it affects $24.3 \%$ of school-age children and $19.0 \%$ of adolescents. ${ }^{(1,3)}$

Quality of life is defined as the perception that individuals have of their position in life, in the context of the culture and system of values in which they live and in relation to their objectives, expectations, standards, and concerns. Quality of life can change according to the environment and the experiences had up to that point, as well as in response to certain diseases. $(4,5)$

From that perspective, it becomes important to evaluate quality of life in patients with chronic diseases such as asthma, because they can impair quality of life in its various biopsychosocial domains and can affect the daily lives of the affected population. ${ }^{(6,7)}$ In addition, children and adolescents deserve special attention, because asthma affects not only the individuals with the disease, but also their caregivers, thereby altering the family routine and the quality of life of all involved. ${ }^{(8-10)}$

Children and adolescents with well-controlled asthma and lower asthma severity, which lead to a reduction in symptoms and medication use, can have a better quality of life. ${ }^{(11-13)}$ The present study is warranted because it is necessary to characterize quality of life in children and adolescents with asthma treated at asthma referral centers. The understanding of the extent to which asthma control status and asthma severity can affect quality of life will help establish therapeutic, environmental, and behavioral strategies, resulting in increased awareness within the health care system as a whole, so that interventions allowing a favorable disease outcome are promoted.

The objective of the present study was to evaluate quality of life according to the level of asthma control and degree of asthma severity in children and adolescents treated at an asthma referral center.

Correspondence to:

Adyléia Aparecida Dalbo Contrera Toro. Rua Tessália Vieira de Camargo, 126, Cidade Universitária Zeferino Vaz, CEP 13083-887, Campinas, SP, Brasil.

Tel.: 5519 3521-8983. E-mail: dalbotoro@terra.com.br

Financial support: None. 


\section{METHODS}

This was an observational, cross-sectional, analytical clinical study conducted at the Pulmonary Physiology Laboratory of the Center for Pediatric Studies of the Universidade Estadual de Campinas (Unicamp, State University at Campinas), in the state of São Paulo, Brazil, between November of 2013 and January of 2015.

We included all children and adolescents $7-17$ years of age and diagnosed with atopic asthma from the Pediatric Pulmonology Outpatient Clinic of the Unicamp Hospital de Clínicas. ${ }^{(1,2)}$ We excluded subjects with cardiac comorbidities resulting in significant hemodynamic changes; those with respiratory diseases resulting in anatomical and structural changes confirmed by ancillary tests; those with cognitive or motor limitations that could compromise their performance in or understanding of the tests; and those who had an exacerbation on the day of testing.

Asthma control was assessed by the Asthma Control Test (ACT), which has been validated for use in Brazil and consists of five questions regarding signs, symptoms, and rescue medication use in the last four weeks. ${ }^{(14-16)}$ In the present study, the following ACT scores were used for defining the level of asthma control: controlled asthma (CA), 25 points; partially controlled asthma (PCA), 20-24 points; and uncontrolled asthma (UA), $<19$ points. ${ }^{(1,14-16)}$

The classification of asthma severity was based on the modified criteria of the Global Initiative for Asthma guidelines, through analysis of the following parameters: symptoms; nocturnal awakenings; rescue medication use; activity limitation; and $\mathrm{FEV}_{1} \cdot{ }^{(1,17,18)}$ As a result, asthma patients were divided into three groups: mild asthma (MiA); moderate asthma (MoA); and severe asthma (SA). This classification always took into account the most severe clinical or functional manifestation.

Quality of life was analyzed by using the Paediatric Asthma Quality of Life Questionnaire (PAQLQ), which has been validated for use in Brazil and consists of 23 questions divided into three domains. ${ }^{(19)}$ The activity limitation domain includes five questions regarding the discomfort that the disease causes during certain activities; the symptoms domain, which consists of ten questions, refers to the discomfort that asthma attacks, cough, dyspnea, wheezing, chest tightness, and nocturnal awakenings cause in children and adolescents; and the emotional function domain, which consists of eight questions, addresses the frequency at which asthma makes patients feel angry, feel afraid because of an asthma attack, feel different from others or excluded, and feel irritated or upset because they cannot keep pace with others. ${ }^{(5,19,20)}$ Responses were made on a 7-point scale, on which 1 indicates the most severe impairment and 7 indicates no impairment at all. $(5,19,20)$ All items have equal weight, and, in addition to the domain scores, the arithmetic means of the responses to the 23 questions is calculated to give an overall score. ${ }^{(5,19,20)}$
In order to analyze the extent to which asthma control status and asthma severity affected the quality of life of the children and adolescents included in the study, patient quality of life was classified as follows (on the basis of the PAQLQ score): minimal or no impairment ( $\geq 6.0$ points); moderate impairment (3.0-5.9 points); and severe impairment ( $<3.0$ points). ${ }^{(11)}$

The data were processed with the Statistical Package for the Social Sciences for Windows, version 16.0 (SPSS Inc., Chicago, IL, USA).

Categorical variables were presented in a descriptive fashion, and differences were analyzed with the Fisher-Freeman-Halton test, bilateral probability being estimated by the Monte Carlo method. Kruskal-Walli. In order to compare the distributions of nonparametric quantitative variables among three groups, we used the Kruskal-Wallis test, using a nonparametric multiple comparison test when significant differences were found. In all cases, the level of significance was set at 5\%.

This study was submitted to and approved by the Research Ethics Committee of the Unicamp School of Medical Sciences (Ruling no. 438.481/2013). The parents or legal guardians of all children and adolescents participating in the study gave written informed consent.

\section{RESULTS}

We evaluated all patients diagnosed with atopic asthma who were treated at the Pediatric Pulmonology Outpatient Clinic of the Unicamp Hospital de Clínicas during the study period. We selected 136 patients on the basis of the inclusion criteria. Of those, 14 were excluded because they had heart disease resulting in significant hemodynamic changes; 18 were excluded because of other respiratory comorbidities, such as bronchiectasis and bronchiolitis obliterans; 2 were excluded because of cognitive limitations; and 2 were excluded because of motor limitations.

The mean age of the 100 patients included in the study was $11.22 \pm 2.91$ years, with a median of 11.20 (7.00-17.60) years. Of the 100 patients, 55 (55.0\%) were male and $45(45.0 \%)$ were female.

Participants were divided into three groups according to the level of asthma control: the CA, PCA, and UA groups, which included 27 patients $(27.0 \%), 33$ patients $(33.0 \%)$, and 40 patients $(40.0 \%)$, respectively. Of the 27 children and adolescents in the CA group, 21 (77.8\%) had MiA, whereas $6(22.2 \%)$ had MoA and none had SA. In the PCA group, $12(36.9 \%)$ had MiA, $12(36.9 \%)$ had MoA, and $9(27.3 \%)$ had SA. In the UA group, only 1 (2.5\%) had MiA, 1 (2.5\%) had MoA, and $38(95.0 \%)$ had SA. Therefore, the MiA, MoA, and SA groups included 34 patients (34.0\%), 19 patients $(19.0 \%)$, and 47 patients (47.0\%), respectively.

We found an association between asthma control and asthma severity ( $p<0.001)$; the patients in the SA group were significantly more likely to belong to 
the UA group (OR $=107.67 ; 95 \% \mathrm{CI}: 21.98-527.3$; $p<0.001)$.

We found no association between gender and asthma control or between gender and asthma severity.

When comparing the asthma control groups, we found no significant differences in age, Z-score for height, or BMI (Table 1). As for the asthma severity groups, the MoA group had a significantly higher mean age than did the SA group, but there were no differences among the groups in terms of $Z$ scores for height or BMI (Table 2), which makes them comparable.

The distribution of means and standard deviations of the overall PAQLQ score, as well as of the scores for the activity limitation, symptoms, and emotional function domains of the PAQLQ, is shown in Tables 3 and 4. When analyzing the values in terms of asthma control and asthma severity, we found significant differences in all of the parameters evaluated ( $p<0.001$ ).

The CA and the PCA groups showed significantly higher values for the overall PAQLQ score and all PAQLQ domains than did the UA group ( $p<0.001$ for all; Table 3 ). The MiA group showed significantly higher values for the overall PAQLQ score and the PAQLQ symptoms and emotional function domains than did the MoA and the SA groups ( $p<0.001$ for all). In contrast, when we compared the MiA and the MoA groups in terms of the scores for the PAQLQ activity limitation domain, we found no significant difference (Table 4). In both cases, the PAQLQ activity limitation domain was the most affected.
The distribution of the degree of impairment reported by the patients in the PAQLQ components (overall score and domains), by level of asthma control and by asthma severity, is shown in Tables 5 and 6, respectively. Significant differences were found in all components ( $p$ $<0.001$ for all). In terms of the overall score, $37.0 \%$ of the patients had minimal or no impairment; $57.0 \%$ had moderate impairment; and $6.0 \%$ had severe impairment. These 6 participants who reported severe impairment of their quality of life belonged to the UA and the SA groups (Tables 5 and 6).

In terms of the activity limitation domain, $31 \%$ of the study participants had minimal or no impairment, $58 \%$ had moderate impairment, and $11 \%$ had severe impairment. Of the 31 individuals with minimal or no impairment, $58.1 \%$ belonged to the CA group, whereas $64.5 \%$ belonged to the MiA group (Tables 5 and 6 ).

Analysis of the symptoms domain showed that $49 \%$ of the children and adolescents had minimal or no impairment, $45 \%$ had moderate impairment, and $6 \%$ had severe impairment. As was true for the overall score, the 6 subjects with severe impairment belonged to the UA and the SA groups (Tables 5 and 6).

Assessment of the emotional function domain showed that $55 \%$ of the subjects had minimal or no impairment, $36 \%$ had moderate impairment, and $9 \%$ had severe impairment. Of the participants with minimal or no impairment, 23 belonged to the CA group and 30 belonged to the MiA group (Tables 5 and 6).

Table 1. Distribution of age (in years), $Z$ scores for height, and BMI in the children and adolescents in the study, by level of asthma control.

\begin{tabular}{lccccccccc} 
Variable & Group & $\mathbf{n}$ & Mean & SD & Minimum & Median & Maximum & $\mathbf{p}$ \\
\multirow{3}{*}{ Age } & CA & 27 & 11.26 & 2.78 & 7.3 & 11.2 & 17.2 & \\
& PCA & 33 & 11.70 & 3.23 & 7.2 & 11.4 & 17.6 & 0.473 \\
& UA & 40 & 10.80 & 2.71 & 7.0 & 10.8 & 17.2 & \\
\multirow{3}{*}{ Height } & CA & 27 & 0.05 & 1.14 & -2.19 & -0.22 & 1.96 & \\
& PCA & 33 & -0.14 & 0.87 & -1.58 & -0.26 & 1.96 & 0.682 \\
& UA & 40 & -0.16 & 1.04 & -2.43 & -0.10 & 1.96 & \\
\multirow{3}{*}{ BMI } & CA & 27 & 0.23 & 1.36 & -2.61 & 0.69 & 2.47 & \\
& PCA & 33 & 0.48 & 1.50 & -2.40 & 0.39 & 3.35 & 0.491 \\
& UA & 40 & 0.71 & 1.34 & -1.74 & 0.75 & 1.34 & \\
\hline
\end{tabular}

CA: controlled asthma; PCA: partially controlled asthma; and UA: uncontrolled asthma. Kruskal-Wallis test.

Table 2. Distribution of age (in years), $\mathrm{Z}$ scores for height, and BMI in the children and adolescents in the study, by asthma severity.

\begin{tabular}{lccccccccc} 
Variable & Group & $\mathbf{n}$ & Mean & SD & Minimum & Median & Maximum & $\mathbf{p}$ \\
\multirow{2}{*}{ Age } & MiA & 34 & 11.21 & 2.79 & 7.2 & 11.2 & 17.2 & \\
& MoA & 19 & 12.47 & 3.23 & 7.8 & 13.6 & 17.6 & 0.043 \\
& SA & 47 & 10.62 & 2.68 & 7.0 & 10.8 & 17.2 & \\
\multirow{3}{*}{ Height } & MiA & 34 & -0.14 & 1.01 & -2.19 & -0.30 & 1.96 & \\
& MoA & 19 & -0.07 & 1.01 & -1.58 & -0.26 & 1.91 & 0.911 \\
& SA & 47 & -0.08 & 1.03 & -2.43 & -0.01 & 1.96 & & \\
\multirow{2}{*}{ BMI } & MiA & 34 & 0.38 & 1.49 & -2.61 & 0.61 & 3.35 & \\
& MoA & 19 & 0.34 & 1.19 & -1.51 & 0.65 & 2.43 & 0.614 \\
\hline
\end{tabular}

MiA: mild asthma; MoA: moderate asthma; and SA: severe asthma. Kruskal-Wallis test and multiple comparison test (age: $M O A>S A)$. 
Table 3. Distribution of the values for the Paediatric Asthma Quality of Life Questionnaire components, by level of asthma control.

\begin{tabular}{|c|c|c|c|c|c|c|c|}
\hline Variable & Group & Mean & SD & Minimum & Median & Maximum & $\mathbf{p}$ \\
\hline \multirow{3}{*}{ Overall } & $\mathrm{CA}$ & 6.39 & 0.88 & 3.92 & 6.61 & 7.00 & \multirow{3}{*}{$<0.001$} \\
\hline & PCA & 5.83 & 0.84 & 3.65 & 5.20 & 7.00 & \\
\hline & UA & 4.20 & 1.16 & 1.50 & 4.44 & 6.10 & \\
\hline \multirow{3}{*}{ Activity limitation } & $\mathrm{CA}$ & 6.16 & 1.17 & 3.40 & 7.00 & 7.00 & \multirow{3}{*}{$<0.001$} \\
\hline & PCA & 5.51 & 1.09 & 2.20 & 5.40 & 7.00 & \\
\hline & UA & 3.73 & 1.09 & 1.60 & 4.00 & 6.00 & \\
\hline \multirow{3}{*}{ Symptoms } & CA & 6.51 & 0.77 & 4.20 & 6.60 & 7.00 & \multirow{3}{*}{$<0.001$} \\
\hline & PCA & 6.02 & 0.77 & 3.80 & 6.10 & 7.00 & \\
\hline & UA & 4.33 & 1.37 & 1.20 & 4.40 & 6.70 & \\
\hline \multirow{3}{*}{$\begin{array}{l}\text { Emotional } \\
\text { function }\end{array}$} & $\mathrm{CA}$ & 6.49 & 0.98 & 2.75 & 6.87 & 7.00 & \multirow{3}{*}{$<0.001$} \\
\hline & PCA & 5.96 & 1.14 & 1.63 & 6.37 & 7.00 & \\
\hline & UA & 4.54 & 1.54 & 1.25 & 4.87 & 6.63 & \\
\hline
\end{tabular}

CA: controlled asthma; PCA: partially controlled asthma; and UA: uncontrolled asthma. Kruskal-Wallis test and multiple comparison test (CA > UA and PCA > UA for all variables).

Table 4. Distribution of the values for the Paediatric Asthma Quality of Life Questionnaire components, by asthma severity.

\begin{tabular}{|c|c|c|c|c|c|c|c|}
\hline Variable & Group & Mean & SD & Minimum & Median & Maximum & $\mathbf{p}$ \\
\hline \multirow{3}{*}{ Overall } & $\mathrm{MiA}$ & 6.37 & 0.63 & 4.90 & 6.50 & 7.00 & \multirow{3}{*}{$<0.001$} \\
\hline & MoA & 5.56 & 1.09 & 3.65 & 5.48 & 7.00 & \\
\hline & SA & 4.49 & 1.31 & 1.50 & 4.56 & 7.00 & \\
\hline \multirow{3}{*}{ Activity limitation } & MiA & 6.02 & 1.09 & 3.60 & 6.40 & 7.00 & \multirow{3}{*}{$<0.001$} \\
\hline & MoA & 5.32 & 1.37 & 2.20 & 5.20 & 7.00 & \\
\hline & SA & 4.09 & 1.32 & 1.60 & 4.10 & 7.00 & \\
\hline \multirow{3}{*}{ Symptoms } & MiA & 6.50 & 0.56 & 5.20 & 6.70 & 7.00 & \multirow{3}{*}{$<0.001$} \\
\hline & MoA & 5.69 & 1.04 & 3.80 & 5.80 & 7.00 & \\
\hline & SA & 4.66 & 1.48 & 1.20 & 4.70 & 7.00 & \\
\hline \multirow{3}{*}{ Emotional function } & MiA & 6.59 & 0.54 & 5.00 & 6.75 & 7.00 & \multirow{3}{*}{$<0.001$} \\
\hline & MoA & 5.69 & 1.22 & 2.75 & 6.12 & 7.00 & \\
\hline & SA & 4.71 & 1.63 & 1.25 & 5.06 & 7.00 & \\
\hline
\end{tabular}

MiA: mild asthma; MoA: moderate asthma; and SA: severe asthma. Kruskal-Wallis test and multiple comparison test: (overall: MiA > MoA; MiA > SA; and MoA > SA); (activity limitation: MiA > SA; MoA > SA); and (symptoms and emotional function: MiA > MoA; MiA > SA).

\section{DISCUSSION}

Our data demonstrate that quality of life is directly related to asthma control and asthma severity in children and adolescents from a referral center.

Roncada et al. conducted a systematic review of questionnaires that have been validated and used for evaluating quality of life in children and adolescents with asthma, concluding that the PAQLQ is the most suitable for use in the Brazilian population. ${ }^{(21)}$ Therefore, the data of the present study were compared with those of other studies that used the same questionnaire.

Our results for the overall PAQLQ score corroborate those of the validation study of the PAQLQ for use in Italy, in which the authors found that the questionnaire correlates well with asthma control and asthma severity and that lower values for the overall PAQLQ score are observed in pediatric patients with poorly controlled asthma and greater asthma severity. ${ }^{(6)}$

Studies have demonstrated that asthma control is directly related to a better quality of life, and, consequently, there is less impairment in social interaction and in the presence of physical and emotional changes in the asthma population. ${ }^{(8,22-26)}$ Al-Gewely et al. evaluated quality of life in children and adolescents with asthma in Egypt by using the PAQLQ and also found higher scores in the group with controlled asthma. ${ }^{(27)}$

When following children and adolescents with asthma at three hospitals in Spain for five weeks, Tauler et al. evaluated asthma severity, quality of life, diary PEF, the global index of change, and the general health perception scale. ${ }^{(28)}$ The authors found that the patients with mild intermittent or mild persistent asthma showed higher values for the overall score than did those with moderate or severe persistent asthma. In our study, the MiA group also showed higher values than did the MoA and the SA groups.

In contrast, in a validation study of the PAQLQ conducted in Turkey, no differences were found in the overall score between the MiA and the MoA groups, a finding the authors attributed to the fact that they did not include patients with SA, and, therefore, the comparison involved only children and adolescents with MiA or MoA. ${ }^{29}$

The activity limitation domain was the PAQLQ component with the lowest values in the asthma control 
Table 5. Distribution of the cases by level of asthma control and by degree of impairment reported in the components of the Paediatric Asthma Quality of Life Questionnaire.

\begin{tabular}{|c|c|c|c|c|c|}
\hline Variable & $\begin{array}{c}\text { CA } \\
n(\%) \\
27(27.0)\end{array}$ & $\begin{array}{c}\text { PCA } \\
n(\%) \\
33(33.0)\end{array}$ & $\begin{array}{c}\text { UA } \\
n(\%) \\
40(40.0)\end{array}$ & $\begin{array}{c}\text { Cases } \\
\text { n } \\
100\end{array}$ & $\mathbf{p}$ \\
\hline \multicolumn{6}{|l|}{ Overall } \\
\hline Minimal or no impairment & $21(56.8)$ & $14(37.8)$ & $2(5.4)$ & 37 & \multirow{3}{*}{$<0.001$} \\
\hline Moderate impairment & $6(10.5)$ & $19(33.3)$ & $32(56.1)$ & 57 & \\
\hline Severe impairment & $0(0.0)$ & $0(0.0)$ & $6(100.0)$ & 6 & \\
\hline \multicolumn{6}{|l|}{ Activity limitation } \\
\hline Minimal or no impairment & $18(58.1)$ & $12(38.7)$ & $1(3.2)$ & 31 & \multirow{3}{*}{$<0.001$} \\
\hline Moderate impairment & $9(15.5)$ & $20(34.5)$ & $29(50.0)$ & 58 & \\
\hline Severe impairment & $0(0.0)$ & $1(9.1)$ & $10(90.9)$ & 11 & \\
\hline \multicolumn{6}{|l|}{ Symptoms } \\
\hline Minimal or no impairment & $23(46.9)$ & $20(40.8)$ & $6(12.2)$ & 49 & \multirow{3}{*}{$<0.001$} \\
\hline Moderate impairment & $4(8.9)$ & $13(28.9)$ & $28(62.2)$ & 45 & \\
\hline Severe impairment & $0(0.0)$ & $0(0.0)$ & $6(100.0)$ & 6 & \\
\hline \multicolumn{6}{|l|}{ Emotional function } \\
\hline Minimal or no impairment & $23(41.8)$ & $21(38.2)$ & $11(20.0)$ & 55 & \multirow{3}{*}{$<0.001$} \\
\hline Moderate impairment & $3(8.3)$ & $11(30.6)$ & $22(61.1)$ & 36 & \\
\hline Severe impairment & $1(11.1)$ & $1(11.1)$ & 7 (77.9) & 9 & \\
\hline
\end{tabular}

CA: controlled asthma; PCA: partially controlled asthma; and UA: uncontrolled asthma. Fisher-Freeman-Halton test.

Table 6. Distribution of the cases by asthma severity and by degree of impairment reported in the components of the Paediatric Asthma Quality of Life Questionnaire.

\begin{tabular}{|c|c|c|c|c|c|}
\hline Variable & $\begin{array}{c}\text { MiA } \\
n(\%) \\
34(34.0)\end{array}$ & $\begin{array}{c}\text { MoA } \\
\text { n (\%) } \\
19(19.0)\end{array}$ & $\begin{array}{c}\text { SA } \\
n(\%) \\
47(47.0)\end{array}$ & $\begin{array}{c}\text { Cases } \\
\text { n } \\
100\end{array}$ & p \\
\hline \multicolumn{6}{|l|}{ Overall } \\
\hline Minimal or no impairment & $24(70.6)$ & $6(6.2)$ & $7(8.9)$ & 37 & \multirow{3}{*}{$<0.001$} \\
\hline Moderate impairment & $10(17.5)$ & $13(22.8)$ & $34(59.6)$ & 57 & \\
\hline Severe impairment & $0(0.0)$ & $0(0.0)$ & $6(100.0)$ & 6 & \\
\hline \multicolumn{6}{|l|}{ Activity limitation } \\
\hline Minimal or no impairment & $20(58.1)$ & 7 (22.6) & 4 (12.9) & 31 & \multirow{3}{*}{$<0,001$} \\
\hline Moderate impairment & $14(24.1)$ & $11(19.0)$ & $33(56.9)$ & 58 & \\
\hline Severe impairment & $0(0.0)$ & $1(9.1)$ & $10(90.9)$ & 11 & \\
\hline \multicolumn{6}{|l|}{ Symptoms } \\
\hline Minimal or no impairment & $28(57.1)$ & $8(6.3)$ & $13(26.5)$ & 49 & \multirow{3}{*}{$<0.001$} \\
\hline Moderate impairment & $6(13.3)$ & $11(24.4)$ & $28(62.2)$ & 45 & \\
\hline Severe impairment & $0(0.0)$ & $0(0.0)$ & $6(100.0)$ & 6 & \\
\hline \multicolumn{6}{|l|}{ Emotional functioning } \\
\hline Minimal or no impairment & $30(54.5)$ & $10(18.2)$ & $15(27.3)$ & 55 & \multirow{3}{*}{$<0.001$} \\
\hline Moderate impairment & $4(11.1)$ & $8(22.2)$ & $24(66.7)$ & 36 & \\
\hline Severe impairment & $0(0.0)$ & $1(5.3)$ & $8(88.9)$ & 9 & \\
\hline
\end{tabular}

MiA: mild asthma; MoA: moderate asthma; and SA: severe asthma. Fisher-Freeman-Halton test.

groups and the asthma severity groups, there being $11 \%$ of children and adolescents in the study who reported severe impairment of their quality of life. In addition, the lowest values in this domain were found in the UA and the SA groups, i.e., the groups with poorest asthma control and greatest asthma severity.

Basso et al. performed spirometry and the six-minute step test (6MST) in, as well as administering physical activity and quality of life questionnaires to, 19 adolescents with asthma (11-15 years of age) in Brazil. (30) Those authors concluded that the sensation of dyspnea and leg fatigue reported at the end of the 6 MST reflected the discomfort that asthma caused during their activities of daily living.

In contrast, Andrade et al. compared physical and cardiorespiratory performance in the six-minute walk test (6MWT) in 40 children with moderate and severe asthma (6-16 years of age) and found that, regarding quality of life assessment, the PAQLQ activity limitation domain had the worst scores and correlated negatively with difference in distance walked.(31) The authors concluded that the performance of the asthma patients 
in the 6MWT, as evaluated on the basis of distance walked, was significantly lower than the predicted values for healthy individuals of the same age group. ${ }^{(31)}$

Therefore, those authors demonstrated that asthma causes discomfort in the daily lives of asthma patients, and that this discomfort will consequently result in greater limitation of activities of daily living in patients with poorly controlled asthma and greater asthma severity. $(30,31)$

Ricci et al. also found lower scores in the PAQLQ activity limitation domain, which was the most affected, together with the symptoms domain; the authors explained that the children and adolescents in that study seemed to be quite worried about asthma attacks and about the limitations that symptoms could impose on their daily lives. ${ }^{(6)}$

The highest means of the CA and the PCA groups are those for the PAQLQ symptoms domain. In the study conducted in Egypt, the symptoms domain was the most affected, a finding that was explained by the medical care limitations in the country or by poor patient adherence to treatment. ${ }^{(27)}$

In a study of children and adolescences with asthma conducted in Portugal, the PAQLQ symptoms domain also was the most affected, which resulted in poor health-related quality-of-life outcomes in the asthma patients. ${ }^{(32)}$

Ayuk et al. evaluated 90 children and adolescents with asthma in Nigeria and also found lower values for the PAQLQ symptoms domain in the adolescents 14-17 years of age; they concluded that older age was a strong predictor of poor quality of life in their study population. (33)

Emotional function was the PAQLQ domain with the highest values in the asthma severity groups, $55 \%$ and $9 \%$ of the participants of the present study reporting minimal/no impairment and severe impairment, respectively. Our findings corroborate those of the study conducted in Turkey, whose authors found higher values in the MiA group than in the MoA group, as well as those of the study conducted in Nigeria, which also found the emotional function domain to be the least affected. ${ }^{(29,33)}$
Cvejoska-Cholakovska et al. followed children and adolescents with asthma in Macedonia for three months; they assessed quality of life and clinical stability to determine the level of asthma control.(34) By the end of the three-month follow-up period, the authors found higher values for the PAQLQ, which indicates improvement in asthma control, the patients with well-controlled asthma having higher scores on the questionnaire. ${ }^{(34)}$ Regarding asthma severity, only the emotional function domain showed differences among the groups. ${ }^{(34)}$

In terms of the extent to which asthma control status and asthma severity affect the quality of life of children and adolescents with asthma, our results are consistent with those reported in the literature, because differences were found in the overall PAQLQ score and the PAQLQ domains among the groups, the scores being higher in the patients with CA and lower asthma severity. ${ }^{(6,22-34)}$

In the present study, as well as in the study by Ricci et al. $^{\left({ }^{(6)}\right.}$ the PAQLQ activity limitation domain was the most affected. In contrast, other studies found the symptoms domain to be the most affected ${ }^{(27,32,33)}$; this difference between findings can be explained by lack of reporting about the exclusion of patients experiencing asthma attacks or about the presence of any asthma attack-related symptoms, which can change the perception of quality of life in this population. ${ }^{(27,32,33)}$

Quality of life appears to be directly related to asthma control and asthma severity in children and adolescents, being better when asthma is well controlled and asthma severity is lower.

Asthma control and asthma severity can affect the quality of life of asthma patients and their family members. Therefore, we emphasize the importance of appropriate follow-up care for this population, with an emphasis on factors that lead to an unfavorable disease outcome, such as nonadherence to treatment, contact with asthma attack-triggering factors, improper use of inhalers, and lack of access to medications and medical care.

\section{REFERENCES}

1. Sociedade Brasileira de Pneumologia e Tisiologia. Diretrizes da Sociedade Brasileira de Pneumologia e Tisiologia para o Manejo da Asma 2012. J Bras Pneumol. 2012;38(Suppl 1):S1-S46.

2. Global Initiative for Asthma (GINA) [homepage on the Internet] Bethesda: GINA; c2014 [cited 2015 Jul 29]. Global Strategy for Asthma Management and Prevention 2014; [Adobe Acrobat document, 148p.]. Available from: http://www.ginasthma.org/documents/4

3. Solé D, Wandalsen GF, Camelo-Nunes IC, Naspitz CK; ISAAC Brazilian Group. Prevalence of symptoms of asthma, rhinitis, and atopic eczema among Brazilian children and adolescents identified by the International Study of Asthma and Allergies in Childhood (ISAAC) - Phase 3. J Pediatr (Rio J). 2006;82(5):341-6. http://dx.doi. org/10.1590/S0021-75572006000600006

4. The World Health Organization Quality of Life assessment (WHOQOL): position paper from the World Health Organization. Soc Sci Med. 1995;41(10):1403-9. http://dx.doi.org/10.1016/02779536(95)00112-K

5. La Scala CS, Naspitz CK, Solé D. Adaptation and validation of the Pediatric Asthma Quality of Life Questionnaire (PAQLQ) in Brazilian asthmatic children and adolescents [Article in Portuguese]. J Pediatr (Rio J). 2005;81(1):54-60. http://dx.doi.org/10.2223/JPED.1283

6. Ricci G, Dondi A, Baldi E, Bendandi B, Giannetti A, Mais M. Use of the Italian version of the Pediatric Asthma Quality of Life Questionnaire in the daily practice: results of a prospective study. BMC Pediatr. 2009;9:30. http://dx.doi.org/10.1186/1471-2431-9-30

7. Souza PG, Sant'Anna CC, March MF. Qualidade de vida na asma pediátrica: revisão da literatura. Rev Paul Pediatr. 2011;29(4):640-4 http://dx.doi.org/10.1590/S0103-05822011000400026

8. Stelmach I, Podlecka D, Smejda K, Majak P, Jerzyńska J, Stelmach $R$, et al. Pediatric asthma caregiver's quality of life questionnaire is a useful tool for monitoring asthma in children. Qual Life Res. 2012;21(9):1639-42. http://dx.doi.org/10.1007/s11136-011-0070-x

9. Silva $\mathrm{CM}$, Barros L, Simões F. Health-related quality of life in paediatric asthma: Children's and parent's perspectives. Phychol Health Med. 2015;20(8):940-54. http://dx.doi.org/10.1080/13548506 .2014 .969745

10. Silva N, Carona C, Crespo C, Canavarro MC. Quality of life in pediatric 
asthma patients and their parents: a meta-analysis on 20 years of research. Expert Rev Pharmacoecon Outcomes Res. 2015;15(3):499519. http://dx.doi.org/10.1586/14737167.2015.1008459

11. Bateman ED, Bousquet J, Keech ML, Busse WW, Clark TJ Pedersen SE. The correlation between asthma control and health status: the GOAL study. Eur Respir J. 2007;29(1):56-62. http://dx.doi. org/10.1183/09031936.00128505

12. Giubert TW, Garris C, Jhingran P, Bonafede M, Tomazzewski KJ, Bonus $\mathrm{T}$, et al. Asthma that is not well-controlled is associated with increased healthcare utilization and decreased quality of life. $J$ Asthma. 2011;48(2):126-32. http://dx.doi.org/10.3109/02770903.201 0.535879

13. Miadich SA, Everhart RS, Borschuk AP, Winter MA, Fiese BH. Quality of Life in Children With Asthma: A Developmental Perspective. J Pediatr Psychol. 2015:40(7)672-9. http://dx.doi.org/10.1093/jpepsy/ jsv002

14. Nathan RA, Sorkness CA, Kosinski M, Schatz M, Li JT, Marcus P, et al. Development of the asthma control test: a survey for assessing asthma control. J Allergy Clin Immunol. 2004;113(1):59-65. http:// dx.doi.org/10.1016/j.jaci.2003.09.008

15. Thomas M, Kayb S, Pike J, Williams A, Rosenzweig JR, Hillye EV, et al. The Asthma Control Test (ACT) as a predictor of GINA guideline-defined asthma control: analysis of a multinational crosssectional survey. Prim Care Respir J. 2009;18(1):41-9. http://dx.doi. org/10.4104/pcrj.2009.00010

16. Roxo JP, Ponte EV, Ramos DC, Pimentel L, D'Oliveira Júnior A, Cruz AA. Portuguese-language version of the Asthma Control Test. J Bras Pneumol. 2010;36(2):159-66. http://dx.doi.org/10.1590/S180637132010000200002

17. Global Initiative for Asthma (GINA) [homepage on the Internet]. Bethesda: GINA; c2014 [cited 2015 Jul 29]. Global Strategy for Asthma Management and Prevention 2006. Available from: http:// www.ginasthma.org/documents/4

18. Moore WC, Fitzpatrick AM, Li X, Hastie AT, Li H, Meyers DA, et al. Clinical heterogeneity in the severe asthma research program. Ann Am Thorac Soc. 2013;10 Suppl:S118-24. http://dx.doi.org/10.1513/ AnnalsATS.201309-307AW

19. Sarria EE, Rosa RC, Fischer GB, Hirakata VN, Rocha NS, Mattiello R. Field-test validation of the Brazilian version of the Paediatric Asthma Quality of Life Questionnaire. J Bras Pneumol. 2010;36(4):417-24 http://dx.doi.org/10.1590/\$1806-37132010000400005

20. Juniper EF, Guyatt GH, Feeny DH, Ferrie PJ, Griffith LE, Townsend $M$. Measuring quality of life in children with asthma. Qual Life Res. 1996;5(1):35-46. http://dx.doi.org/10.1007/BF00435967

21. Roncada C, Mattiello R, Pitrez PM, Sarria EE. Specific instruments to assess quality of life in children and adolescents with asthma. J Pediatr (Rio J). 2013;89(3):217-25. http://dx.doi.org/10.1016/j. jped.2012.11.010
22. Juniper EF. How important is quality of life in pediatric asthma? Pediatr Pulmonol Suppl. 1997:15:17-21. http://dx.doi.org/10.1002/ (SICI)1099-0496(199709)15+<17::AID-PPUL5>3.0.CO;2-O

23. Juniper EF, O'Byrne PM, Guyatt GH, Ferrie PJ, King DR Development and validation of a questionnaire to measure asthma control. Eur Respir J. 1999;14(4):902-7. http://dx.doi.org/10.1034/ j.1399-3003.1999.14d29.x

24. Bloomberg GR, Chen E. The relationship of psychologic stress with childhood asthma. Immunol Allergy Clin North Am. 2005;25(1):83105. http://dx.doi.org/10.1016/j.iac.2004.09.00

25. Gazzotti MR, Nascimento AO, Montealegre F, Fish J, Jardim JR Level of asthma control and its impact on activities of daily living in asthma patients in Brazil. J Bras Pneumol. 2013;39(5):532-8. http:// dx.doi.org/10.1590/S1806-37132013000500002

26. Gandhi PK, Kenzik KM, Thompson LA, DeWalt DA, Revicki DA Shenkman EA, et al. Exploring factors influencing asthma control and asthma-specific health-related quality of life among children. Resp Res. 2013;14:26. http://dx.doi.org/10.1186/1465-9921-14-26

27. Al-Gewely MS, El-Hosseiny M, Abou Elezz NF, El-Ghoneimy DH, Hassan AM. Health-related quality of life in childhood bronchia asthma. Egypt J Pediatr Allergy Immunol. 2013;11(2):83-93.

28. Tauler E, Vilagut G, Grau G, González A, Sánchez E, Figueras G et al. The spanish version of the paediatric asthma quality of life questionnaire (PAQLQ): metric characteristics and equivalence with the original version. Qual Life Res. 2001;10(1):81-91. http://dx.doi. org/10.1023/A:1016622519987

29. Yüksel H, Yilmaz O, Kirmaz C, Eser E. Validity and reliability of the Turkish translation of the Pediatric Asthma Quality of Life Questionnaire. Turk J Pediatr. 2009;51(2):154-60.

30. Basso RP, Jamami M, Labadessa IG, Regueiro EM, Pessoa BV, Oliveira $A D \mathrm{Jr}$, et al. Relationship between exercise capacity and quality of life in adolescents with asthma. J Bras Pneumol. 2013;39(2):121-7. http://dx.doi.org/10.1590/S1806-37132013000200002

31. Andrade LB, Silva DA, Salgado TL, Figueroa JN, Lucena-Silva N Britto MC. Comparison of the six-minute walk test in children with moderate/severe asthma with reference values for healthy children. J Pediatr (Rio J). 2014:90(3):250-7. http://dx.doi.org/10.1016/j. jped.2013.08.006

32. Guedes ML. Avaliação da qualidade de vida em crianças e adolescentes com asma. [dissertation]. Covilhã (Portugal): Universidade da Beira Interior; 2013.

33. Ayuk AC, Oguonu T. Ikefuna NA, Ibe BC. Asthma control and quality of life in school-age children in Enugu South East, Nigeria. Niger Postgrad Med J. 2014;21(2):160-4

34. Cvejoska-Cholakovska V, Vlaski E, Velic-Stefanovska V. Quality of life in children with asthma as a marker of clinical stability. Macedonian Med Rev. 2014;68(1):21-4. http://dx.doi.org/10.2478/mmr-2014-0004 